\title{
Unusual chromosome polymorphism and heterochromatin variation in the Argentinean population of the necrophagous fly Lucilia sericata (Diptera: Calliphoridae), comparison with other populations and evolutionary aspects
}

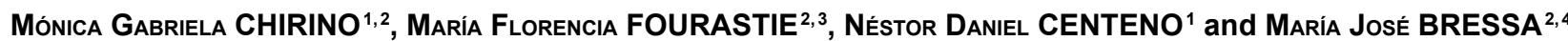 \\ ${ }^{1}$ Laboratorio de Entomología Aplicada y Forense, Departamento de Ciencia y Tecnología, Universidad Nacional de Quilmes, \\ Roque Sáenz Peña 352, B1876BXD Bernal, Buenos Aires, Argentina; e-mails: mchirino@unq.edu.ar, ncenteno@unq.edu.ar \\ ${ }^{2}$ Consejo Nacional de Investigaciones Científicas y Técnicas, C1425FQB Ciudad Autónoma de Buenos Aires, Argentina \\ ${ }^{3}$ Departamento de Ecología, Genética y Evolución, Facultad de Ciencias Exactas y Naturales, Universidad de Buenos Aires, \\ C1428EHA Ciudad Autónoma de Buenos Aires, Argentina; e-mail: ffourastie@ege.fcen.uba.ar \\ ${ }^{4}$ Grupo de Citogenética de Insectos, Departamento de Ecología, Genética y Evolución, Facultad de Ciencias Exactas \\ y Naturales, Universidad de Buenos Aires, C1428EHA Ciudad Autónoma de Buenos Aires, Argentina; \\ e-mail: mjbressa@ege.fcen.uba.ar
}

Key words. Diptera, Calliphoridae, Lucilia sericata, intraspecific variation, chromosome evolution, chromosome polymorphism, constitutive heterochromatin, Argentina

\begin{abstract}
Heterochromatin may vary qualitatively, quantitatively, and in its location both in and between species. There were differences recorded in sex chromosomes, satellite sizes and location of C-bands in specimens of Lucilia sericata (Meigen, 1826) from three localities in the Buenos Aires region, Argentina (Bernal, Castelar, and Buenos Aires City). Mitotic analyses revealed the same diploid chromosome number of $2 n=10+X Y / X X$ (male/female) and the same size, morphology, and C-banding patterns on their autosomes. However, there are different morphotypes of $X$ and $Y$ chromosomes with a distinctive heterochromatin content in both arms. Four morphotypes of $X\left(X_{1}, X_{2}, X_{3}\right.$, and $\left.X_{4}\right)$ and three of $Y\left(Y_{1}, Y_{2}\right.$, and $\left.Y_{3}\right)$ were recorded. The $X$ metacentric and $Y$ subtelocentric chromosomes were identified based on their very large and small sizes, respectively, and both had large heterochromatic blocks. These intraspecific differences are mainly due to quantitative variations in non-coding repetitive sequences located in the arms of both $X$ and $Y$ sex chromosomes. The specimens were very polymorphic both between and within the three localities sampled. Cytogenetic studies on specimens of $L$. sericata from the Nearctic, Palaearctic and Ethiopian regions also report differences in the morphology of the sex chromosomes and their C-banding patterns, some of which may have evolved independently. Our cytogenetic observations on $L$. sericata indicate that the accumulation of heterochromatin in the genome could be involved in chromosomal divergence and karyotype evolution of this species, as demonstrated in other Diptera. The polymorphic sex chromosomes are therefore important for understanding the evolution within species as well as speciation.
\end{abstract}

\section{INTRODUCTION}

The cosmopolitan and geographically widespread blowflies, the Calliphoridae, are a group of great medical, forensic, and veterinary significance (Greenberg, 1991; Byrd \& Castner, 2001; Opletalová et al., 2012). Lucilia sericata (Meigen, 1826) is one of the first insects to arrive at a corpse (Centeno et al., 2002; Ames \& Turner, 2003) and, therefore, is the primary and most accurate indicator of the time of death (Centeno et al., 2002).

Based on morphological differences, 32 species of $\mathrm{Luci}$ lia are described (Stevens \& Wall, 1996; Whitworth, 2010, 2014), with 23 species occurring in the Neotropical Region (South America, Central America, the West Indies and portions of southern Mexico along the east and west coasts).
However, only eight species have been cytogenetically studied, have a karyotype of $2 n=12$ and differ mainly in the amount and distribution of constitutive heterochromatin and in the size and shape of the sex chromosomes (Boyes \& Shewell, 1975; El-Bassiony, 2006; Ullerich \& Schöttke, 2006; Agrawal et al., 2010; Acuña-Morera et al., 2011; Chirino et al., 2015). Analyses of larval mitotic chromosomes of L. sericata from different geographical regions (Argentina, Canada, Colombia, Egypt, United Kingdom, and Germany) indicate they differ in the morphology of their autosomes and sex chromosomes, and have distinctive C-banding patterns (Boyes, 1961; El-Bassiony, 2006; Ullerich \& Schöttke, 2006; Agrawal et al., 2010; AcuñaMorera et al., 2011; Chirino et al., 2015). In Diptera, chang- 


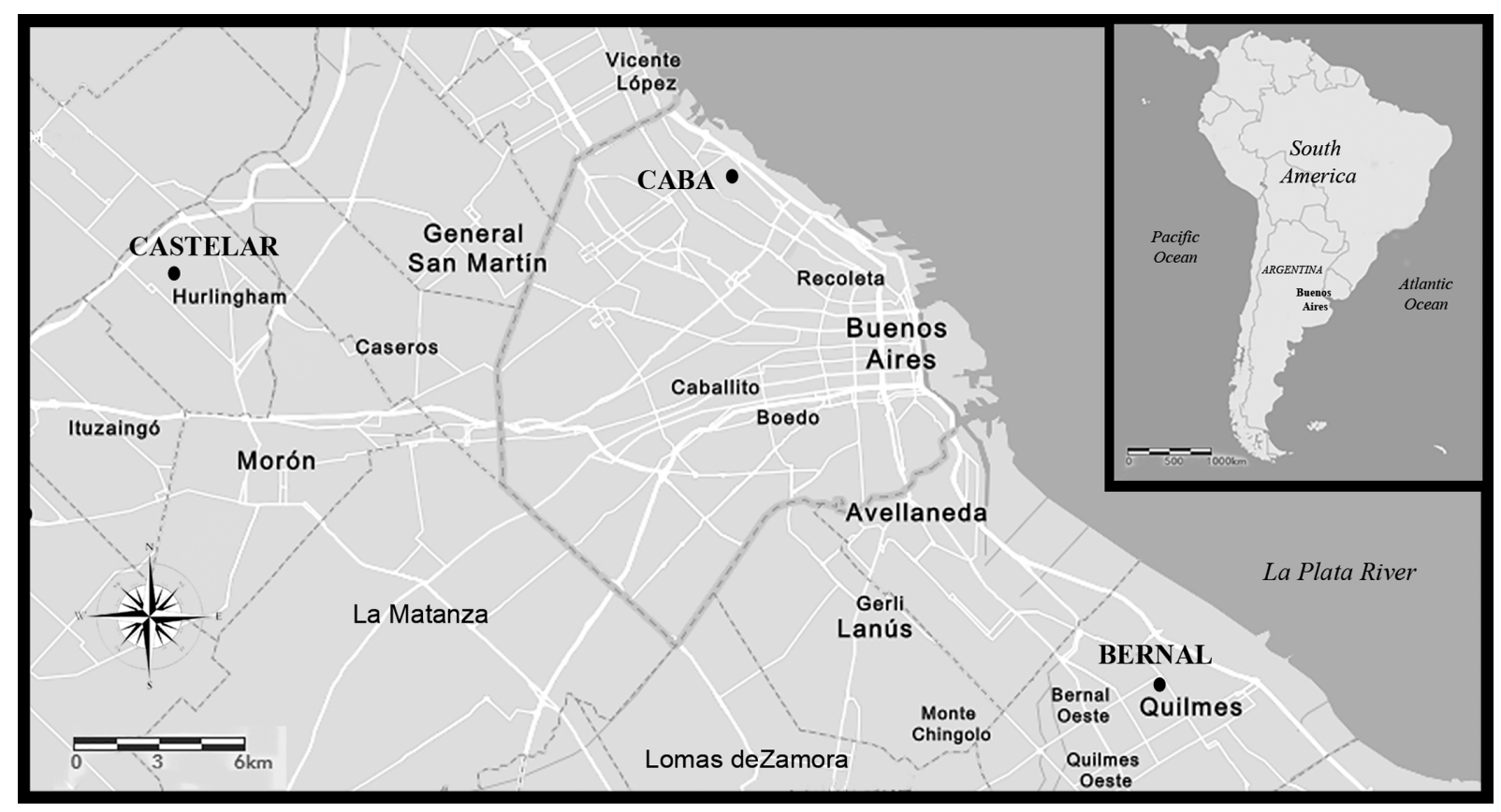

Fig. 1. Map showing the three localities where Lucilia sericata was sampled, indicated by black dots. The bold dotted grey line indicates the geographical border of CABA. The thinner grey lines indicate the geographical borders of the main districts close to CABA. The white lines are the main train tracks.

es in the constitutive heterochromatin in several isolated populations of different species are reported (White, 1973; Baimai, 1998; Rafael \& Tadei, 2000; Selivon et al., 2005; Ullerich \& Schöttke, 2006; Cáceres et al., 2009; Agrawal et al., 2010; Acuña-Morera et al., 2011; Chirino et al., 2015). Moreover, DNA studies on L. sericata from North America detected that there are three subpopulations there based on AFLP genotype analyses (Picard \& Wells, 2010) whereas a random mating occurs in Eastern European flies and there are no subpopulations based on the chaetotaxy of the thorax and eight microsatellite loci (Diakova et al., 2018). Thus, the population genetic structure and morphological features of $L$. sericata may depend on geographic origin and associated differences in life-history traits. The processes of genetic differentiation may include chromosomal rearrangements, leading to diverse chromosome morphologies and variation in inter- and intra-specific constitutive heterochromatin, resulting in quantitative changes in repetitive DNA sequences (Grewal \& Jia, 2007).

The karyotype and C-banding pattern of L. sericata from Argentina are reported in a previous study (Chirino et al., 2015). Here, we determine the C-banding on the autosomes and sex chromosomes in specimens of $L$. sericata from three localities in the Buenos Aires region (Fig. 1) because the $\mathrm{X}$ chromosomes had two distinctive morphologies (Fig. 1c in Chirino et al., 2015). We measured their relative lengths, size of satellites, centromeric index, arm ratio, and distribution and percentage of heterochromatin.

\section{MATERIAL AND METHODS}

\section{Insects}

Females of Lucilia sericata from three localities in the Buenos Aires region, Argentina (Fig. 1) were collected using beef meat as bait, between October 2016 and May 2017. Flies were sampled in
Buenos Aires City (CABA; 34 $36^{\prime} 14^{\prime \prime} \mathrm{S}$ and $\left.58^{\circ} 22^{\prime} 54^{\prime \prime} \mathrm{W}\right)$, Bernal (Buenos Aires Province; $34^{\circ} 42^{\prime} 24^{\prime \prime} \mathrm{S}$ and $58^{\circ} 16^{\prime} 39^{\prime \prime} \mathrm{W}$ ) and Castelar (Buenos Aires Province; 34 $40^{\circ} 00^{\prime \prime} \mathrm{S}$ and $58^{\circ} 40^{\prime} 00^{\prime \prime} \mathrm{W}$ ) (Fig. 1). Specimens were identified using Whitworth's key (2014) and transferred to different cages at $22 \pm 2{ }^{\circ} \mathrm{C}$ and $60 \pm 5 \%$ relative humidity to allow them to oviposit on pieces of beef meat. After hatching, first-instar larvae were transferred to rearing cages and were observed daily until the larvae reached the third instar.

\section{Chromosome preparations}

Mitotic chromosomes were obtained from the neural ganglia of third-instar larvae. Larval specimens from each locality were sexed (10 females and 8 males reared from four females caught in CABA, 7 females and 8 males from three females caught in Bernal, and 12 females and 12 males from four females caught in Castelar were analysed). Brains were dissected in a physiological solution (Glaser, 1917: cited by Lockwood, 1961) using fine forceps, swollen for $10 \mathrm{~min}$ in a $0.075 \mathrm{M} \mathrm{KCl}$ hypotonic solution and fixed for $15 \mathrm{~min}$ in freshly prepared Carnoy fixative (ethanol : chloroform : glacial acetic acid, $6: 3: 1$ ). Cells were dissociated in $20 \mu \mathrm{l}$ of $60 \%$ acetic acid and spread on a slide using a heating plate at $45^{\circ} \mathrm{C}$ (Traut, 1976). The preparations were dehydrated in an ethanol series (70, 80, and $96 \%, 30 \mathrm{~s}$ each) and stored at $-20^{\circ} \mathrm{C}$ until use.

\section{Chromosome C-banding, DNA measurements and idiograms}

Heterochromatin content and distribution were analysed by means of C-banding according to Sumner (1972) and Chirino et al. (2009), with the following modifications: slides were treated with $0.2 \mathrm{~N} \mathrm{HCl}$ at $60^{\circ} \mathrm{C}$ for $10 \mathrm{~min}, 5 \%$ saturated solution of $\mathrm{Ba}(\mathrm{OH})_{2}$ at $25^{\circ} \mathrm{C}$ for $20 \mathrm{~min}$ and $2 \times \mathrm{SSC}$ at $60^{\circ} \mathrm{C}$ for $60 \mathrm{~min}$. The pre-treated preparations were then stained with DAPI (4'6-diamidino-2-phenylindole) (Fluka BioChemika, Sigma-Aldrich Production $\mathrm{GmbH}$, Buchs, Switzerland) for $20 \mathrm{~min}$.

To determine the karyotype, we measured at least twenty wellspread mitotic metaphases for each female and male larva of $L$. sericata from CABA, Bernal, and Castelar. The total chromo- 

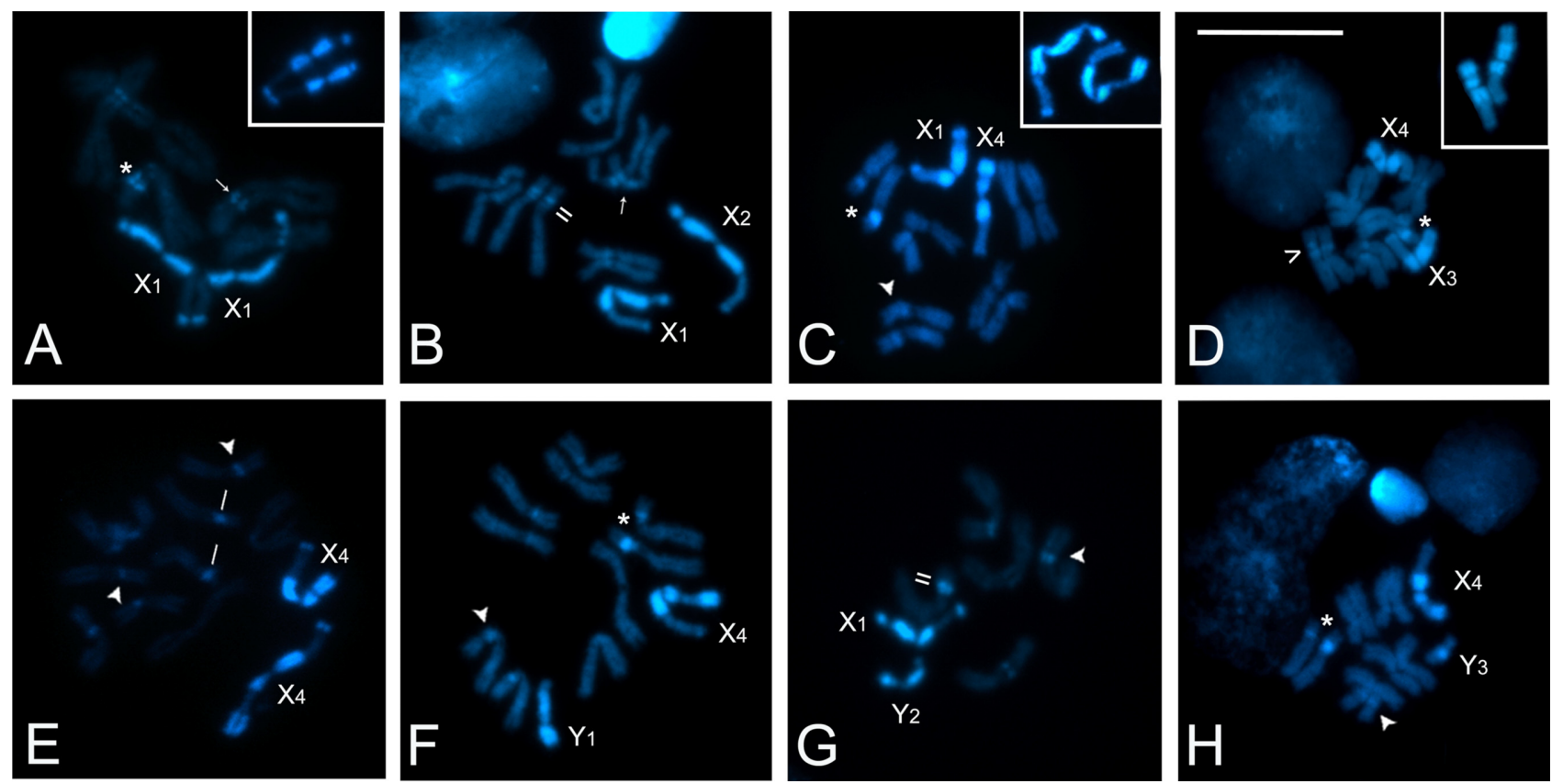

Fig. 2. C-banding patterns on the chromosomes of female and male $L$. sericata from CABA, Bernal, and Castelar, stained with DAPI. Morphotypes of sex chromosomes and patterns on the $2^{\text {nd }}$ and $3^{\text {rd }}$ chromosomal pairs. A - female $X_{1} X_{1}, D D, B b, B e r n a l ; B-$ female $X_{1} X_{2}$, DD, BB, CABA; C - female $X_{1} X_{4}$, SS, Bb, CABA; D - female $X_{3} X_{4}$, DS, Bb, CABA; E - female $X_{4} X_{4}, S S$, bb, Castelar; $F-$ male $X_{4} Y_{1}, S S$, $\mathrm{Bb}$, Castelar; $\mathrm{G}$ - male $\mathrm{X}_{1} \mathrm{Y}_{2}$, SS, BB, Bernal; $\mathrm{H}$ - male $\mathrm{X}_{4} \mathrm{Y}_{3}$, SS, Bb, CABA. Heteromorphic sex pair in detail (A, C-D). Very large Cpositive blocks are observed in the pairs of autosomes II and III, and both $X$ and $Y$ sex chromosomes. $X, Y-$ sex chromosomes. Arrows indicate the double $\mathrm{C}+$ heterochromatin band (DD) near the secondary constriction on chromosome 2 . Arrowheads show the single $\mathrm{C}+$ heterochromatin band (SS) near the secondary constriction on chromosome 2. Open arrowheads indicate the heterozygous C-band pattern (DS) on the secondary constriction on chromosome 2. Double lines indicate the C-block pattern (BB) on the secondary constriction on chromosome 3. Single lines indicate the C-band pattern $(\mathrm{bb})$ on the secondary constriction on chromosome 3 . Asterisks indicate the presence of one C-block $(B)$ and one C-band $(b)$, heterozygous state $(B b)$, on the secondary constriction on chromosome $3 . B a r=10 \mu \mathrm{m}$.

some length measurements (TCL; mean $\pm \mathrm{SE}$ ) of all bivalents and sex chromosomes, relative average length $(\mu \mathrm{m}$; length of an autosomal bivalent as a percentage of the TCL) and relative chromosomal percentage (\%) were obtained using MicroMeasure software for Windows, version 3.3 (Reeves \& Tear, 2000). Measurements were of chromosomes at metaphase. Differences in the lengths of chromosomes of males and females from the three localities were analysed using Kruskal-Wallis ANOVAs on ranks for global comparisons $(P<0.05)$, followed by Kruskal-Wallis all-pairwise comparison test for contrasts between treatments because the data were not normally distributed and did not show homoscedasticity. Statistical analyses were performed using InfoStat software (Di Rienzo et al., 2015). The constitutive heterochromatin percentage as the $\mathrm{C}$-positive area divided by the TCL was calculated. The $\mathrm{C}$-banded region in the short and long arms of pairs II and III and in both sex chromosomes was calculated as the ratio between the $\mathrm{C}$-positive area and the arm length. The heterochromatic blocks in the satellites of the $\mathrm{X}$ and $\mathrm{Y}$ chromosome were determined as the $\mathrm{C}$-positive area of the satellite concerning its total length. Idiograms illustrating the $\mathrm{C}$-band patterns were based on the results obtained from several individuals.

\section{Microscopy and image processing}

Preparations were observed under a Leica DM2000 epifluorescence microscope equipped with a Leica DFC345 FX CCD camera and Leica Application Suite (LAS), version 3.8 (Leica Microsystems Imaging Solutions Ltd., Cambridge, UK). Blackand-white images of chromosomes were recorded, pseudo-coloured and processed with Adobe Photoshop CS6 Version 6.1 software.

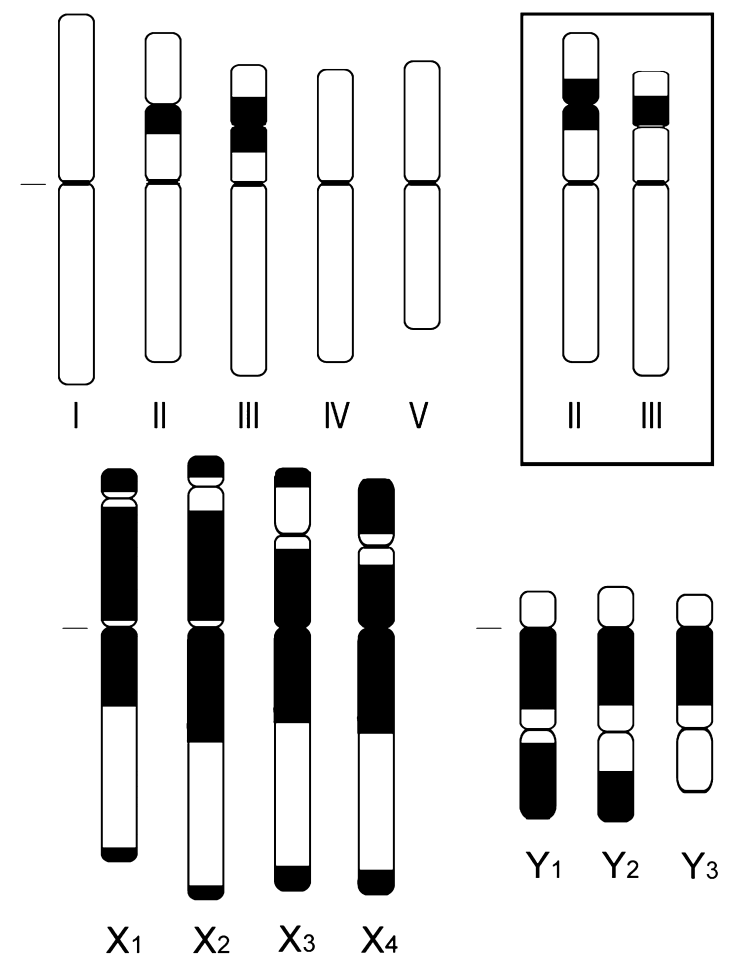

Fig. 3. Comparative idiograms of autosomes and sex chromosomes in females and males of $L$. sericata, based on the C-banded karyotypes. $\mathrm{X}, \mathrm{Y}-\mathrm{sex}$ chromosomes. The centromere positions are marked by a line next to each type of chromosome. The euchromatic and heterochromatic regions on the chromosomes are in white and black, respectively. 
Table 1. Comparison of the total lengths ( $\mathrm{TL})$, arm lengths, centromeric index (Cl), and percentage of haploids (\%) in Lucilia sericata (mean $\pm \mathrm{SE})$.

\begin{tabular}{|c|c|c|c|c|c|c|}
\hline Chromosome pair & $\mathrm{TL}(\mu \mathrm{m})^{*}$ & Short arm $(\mu \mathrm{m})$ & Long arm $(\mu \mathrm{m})$ & $\mathrm{Cl}$ & $2^{\text {nd }}$ const. ${ }^{* *}$ & Set $(\%)$ \\
\hline 1 & $6.53 \pm 0.99 b$ & $3.19 \pm 0.70$ & $3.83 \pm 0.82$ & $0.45(\mathrm{~m})$ & - & 9.74 \\
\hline 2 & $5.75 \pm 0.83 c$ & $2.80 \pm 0.61$ & $3.39 \pm 0.78$ & $0.45(\mathrm{~m})$ & $1.42 \pm 0.43$ & 8.60 \\
\hline 3 & $5.42 \pm 0.94 \mathrm{~d}$ & $2.18 \pm 0.48$ & $3.61 \pm 0.81$ & $0.38(\mathrm{~m}-\mathrm{sm})$ & $1.06 \pm 0.33$ & 7.99 \\
\hline 4 & $5.16 \pm 0.86 \mathrm{e}$ & $2.13 \pm 0.49$ & $3.39 \pm 0.82$ & 0.39 (m-sm) & - & 7.64 \\
\hline 5 & $4.66 \pm 0.83 f$ & $2.23 \pm 0.50$ & $2.75 \pm 0.62$ & $0.45(\mathrm{~m})$ & - & 9.74 \\
\hline $\mathrm{X}_{1}$ & $7.49 \pm 1.08 \mathrm{a}$ & $2.77 \pm 0.31$ & $4.31 \pm 0.62$ & $0.43(\mathrm{~m})$ & $2.24 \pm 0.47$ & 11.38 \\
\hline$x_{2}$ & $8.00 \pm 0.84 a$ & $2.98 \pm 0.27$ & $4.86 \pm 0.58$ & $0.42(\mathrm{~m})$ & $2.43 \pm 0.63$ & 11.50 \\
\hline$x_{3}^{2}$ & $6.97 \pm 0.88 a$ & $2.77 \pm 0.43$ & $4.37 \pm 0.77$ & $0.45(\mathrm{~m})$ & $1.59 \pm 0.37$ & 11.70 \\
\hline$X_{4}$ & $6.73 \pm 0.89 a$ & $2.53 \pm 0.48$ & $4.40 \pm 1.00$ & $0.43(\mathrm{~m})$ & $1.41 \pm 0.43$ & 11.41 \\
\hline$Y_{1}^{4}$ & $4.70 \pm 1.01 \mathrm{f}$ & $0.67 \pm 0.10$ & $3.33 \pm 0.49$ & 0.16 (st) & $1.73 \pm 0.33$ & 6.30 \\
\hline$Y_{2}$ & $4.50 \pm 0.81 \mathrm{f}$ & $0.70 \pm 0.10$ & $3.39 \pm 0.48$ & 0.17 (st) & $1.80 \pm 0.20$ & 5.95 \\
\hline $\mathrm{Y}_{3}^{2}$ & $4.11 \pm 0.80 \mathrm{f}$ & $0.56 \pm 0.21$ & $2.88 \pm 0.95$ & 0.20 (st) & $1.74 \pm 0.55$ & 5.36 \\
\hline
\end{tabular}

Morphology of chromosomes. $\mathrm{m}$ - metacentric, $\mathrm{m}$-sm - metacentric-submetacentric, sm - submetacentric, st - subtelocentric. ${ }^{\star}$ Statistical comparisons were analysed using Kruskal-Wallis tests. Different letters indicate significant differences in post-hoc analyses $(P<0.05)$. ${ }^{* *}$ Distance of the secondary constriction concerning the centromere in the short arm of pairs II, III, and X chromosomes, and in the long arm of Y chromosomes. "-" - lack secondary constriction.

\section{RESULTS}

The autosomes from specimens collected from the three localities (CABA, Bernal, and Castelar) were very similar in morphology and size $(H=2.49, P=0.2884)$ and gradually decreased in size $(H=153.95, P<0.0001$; Table 1$)$. Four types of $\mathrm{X}\left(\mathrm{X}_{1}, \mathrm{X}_{2}, \mathrm{X}_{3}, \mathrm{X}_{4}\right)$ and three types of $\mathrm{Y}$ chromosomes $\left(Y_{1}, Y_{2}, Y_{3}\right)$ were distinguished, characterized by differences in the location of the secondary constriction, the size of their satellites and C-banding patterns (Figs 2, 3; Tables 1,2$)$. The $\mathrm{X}$ was larger than the $\mathrm{Y}$ chromosome $(H=$ $216.91, P<0.0001)$. No statistical differences in sizes were detected between the four $\mathrm{X}$ chromosomes or between the three Ys of individuals from the same or different localities. Data for all specimens are shown together (Figs 2, 3; Tables 1, 2). Centromeric C-bands were found on all chromosomes. The variation in the amount of constitutive heterochromatin in the pericentromeric regions (bands and blocks) of autosome pairs II and III and X and Y chromosomes are shown in Figs 2 and 3 and Table 2.

In specimens from all three sites, the autosome pair II had one or two well-defined interstitial C-bands on the short arm associated with the secondary constriction. According to the number of these interstitial C-bands, there were three different patterns in females and males: homozygous for the presence of two C-bands on each short arm (double banding pattern = DD) (Fig. 2A, B), homozygous for the presence of one $\mathrm{C}$-band on each short arm (single banding pattern $=\mathrm{SS})($ Fig. $2 \mathrm{C}, \mathrm{E}-\mathrm{H})$ and heterozygous for the presence of one C-band (S) on the short arm of one homologue and two C-bands (D) on the short arm of the other (Fig. 2D; Table 3). The first two C-banding patterns were predominant in specimens from all three sites, while only one female from each locality showed the DS pattern (Table 3). Furthermore, we observed differences in the size of the heterochromatic blocks around the secondary constriction on the short arms of autosome pair III in both females and males from all three sites. This autosome pair can exhibit one C-block on each short arm (block pattern = BB) (Fig. 2B, G), one C-band on each short arm (band pattern $=$ bb) (Fig. 2E) or it can be heteromorphic for the size of the band, i.e., the C-band has a different size in each homologue (Bb; Fig. 2A, C, D, F, H). The BB and Bb patterns were common in both sexes from all three sites, whereas the bb pattern was rare and not detected in specimens from CABA (Table 3).

Sex chromosomes showed greater variation in the content and distribution of heterochromatic blocks than the autosomes (Figs 2, 3; Table 2). The $\mathrm{X}_{1}$ and $\mathrm{X}_{2}$ chromosomes were very similar in size, relation of arms, small size of their satellites, and percentage of heterochromatin. The $\mathrm{X}_{1}$ chromosome differed from $\mathrm{X}_{2}$ in the content and distribution of the heterochromatic block, with about $75 \%$ of the $\mathrm{X}_{1}$ satellite but only about $50 \%$ of the $\mathrm{X}_{2}$ satellite heterochromatic (Figs 2B, 3). The $\mathrm{X}_{3}$ and $\mathrm{X}_{4}$ chromosomes had larger satellites than $X_{1}$ and $X_{2}$. The satellite of $X_{3}$ was mainly euchromatic (Fig. 2D), with only a small terminal area of heterochromatin, whereas the satellite of $\mathrm{X}_{4}$ was mainly heterochromatic (Fig. 2C-F, H). The morphotypes of $\mathrm{Y}$ also differed in the relative content of heterochromatin

Table 2. Comparison of the percentage of heterochromatin recorded in haploids in Lucilia sericata for each chromosome pair.

\begin{tabular}{ccccc}
\hline $\begin{array}{c}\text { Chromosome } \\
\text { pair }\end{array}$ & TL $(\%)^{*}$ & $\begin{array}{c}\text { Short arm } \\
(\%)^{* *}\end{array}$ & $\begin{array}{c}\text { Long arm } \\
(\%)^{* *}\end{array}$ & $\begin{array}{c}\text { Satellite } \\
(\%)^{\#}\end{array}$ \\
\hline I & $0.26-0.77$ & - & - & - \\
II & $9.43-13.55$ & $19.75-37.77$ & - & - \\
III & $10.00-18.44$ & $27.93-44.52$ & - & - \\
IV & $0.33-1.00$ & - & - & - \\
V & $0.36-1.09$ & - & - & - \\
$\mathrm{X}_{1}$ & 61.35 & 82.36 & 50.75 & 75.65 \\
$\mathrm{X}_{2}$ & 58.99 & 84.50 & 53.86 & 75.48 \\
$\mathrm{X}_{3}$ & 49.91 & 80.31 & 47.03 & 27.06 \\
$\mathrm{X}_{4}$ & 59.95 & 75.76 & 50.47 & 80.61 \\
$\mathrm{Y}_{1}$ & 68.38 & - & 79.39 & 84.31 \\
$\mathrm{Y}_{2}$ & 53.50 & - & 71.09 & 54.64 \\
$\mathrm{Y}_{3}$ & 38.54 & - & 78.81 & - \\
\hline
\end{tabular}

* Differences in C-positive heterochromatin percentage in the total length (TL) of the centromeric and pericentromeric areas of each pair of chromosomes. "-" - lack heterochromatin. ${ }^{* *} \mathrm{C}$-positive heterochromatin percentage in short arm of pairs II and III, and in the heterochromatic blocks in short and long arms of sex chromosomes (including each satellite). "C-positive heterochromatin percentage exclusively recorded in the satellites of $X$ and $Y$ chromosomes. 
Table 3. Number of females and males, for which different numbers of cells were observed, in which II and III autosome pairs were homozygous or heterozygous in Lucilia sericata from CABA, Bernal, and Castelar.

\begin{tabular}{|c|c|c|c|c|c|c|c|c|c|}
\hline \multirow{2}{*}{ Locality } & \multirow{2}{*}{ Sex } & \multicolumn{4}{|c|}{ Autosome pair II } & \multicolumn{4}{|c|}{ Autosome pair III } \\
\hline & & DD & DS & SS & $N(n)^{*}$ & BB & $\mathrm{Bb}$ & $\mathrm{bb}$ & $N(n)^{*}$ \\
\hline \multirow[t]{2}{*}{ Bernal } & $\mathrm{F}$ & $2(65)$ & $1(22)$ & $4(89)$ & $7(176)$ & $3(74)$ & $2(48)$ & $2(54)$ & $7(176)$ \\
\hline & $M$ & $4(40)$ & 0 & $4(22)$ & $8(62)$ & $2(20)$ & $5(38)$ & $1(4)$ & $8(62)$ \\
\hline \multirow[t]{2}{*}{ Castelar } & $\mathrm{F}$ & $3(22)$ & $1(12)$ & $8(90)$ & $12(124)$ & $7(54)$ & $4(46)$ & 1 (13) & $12(113)$ \\
\hline & $M$ & $4(21)$ & 0 & $8(83)$ & $12(104)$ & $3(26)$ & $9(78)$ & 0 & 12 (104) \\
\hline \multirow[t]{3}{*}{ CABA } & $\mathrm{F}$ & $2(11)$ & $1(7)$ & $7(50)$ & $10(68)$ & $4(21)$ & $6(54)$ & 0 & $10(75)$ \\
\hline & $\mathrm{M}$ & $3(40)$ & 0 & $5(72)$ & $8(112)$ & $2(34)$ & $6(78)$ & 0 & $8(112)$ \\
\hline & Total & $18(199)$ & $3(41)$ & $36(406)$ & $57(646)$ & $21(229)$ & $32(342)$ & $4(71)$ & $56(629)$ \\
\hline
\end{tabular}

Abbreviations: F - female, M - male, DD - double banding pattern, SS - single banding pattern, DS - heterozygous for the presence of one C-band D (S) and two C-bands (D), BB - C-block pattern, bb - C-band pattern, Bb - heterozygous for the presence of one C-block (B) and one C-band (b). *Number of adults (and cells) examined of $L$. sericata for each locality and sex.

in the satellite. The $\mathrm{Y}_{1}$ chromosome had the largest fully heterochromatic satellite (Fig. 2F); $\mathrm{Y}_{2}$ had a medium-sized heterochromatic block covering nearly $50 \%$ of its satellite (Fig. 2G), and $\mathrm{Y}_{3}$ had an euchromatic satellite (Fig. 2H).

The polymorphism of sex chromosomes varied both within and between collecting sites. However, the $X_{1}$ and $\mathrm{Y}_{1}$ chromosomes were the commonest morphotypes recorded at all the sites studied (Table 4). Specimens from Bernal were only of the $X_{1}$ morphotype $\left(X_{1} X_{1}\right.$ in females, $\mathrm{X}_{1} \mathrm{Y}_{1}$ or $\mathrm{X}_{1} \mathrm{Y}_{2}$ in males). Samples from Castelar were of all four $\mathrm{X}$ morphotypes; with females of four cytotypes $\left(\mathrm{X}_{1} \mathrm{X}_{4}\right.$, $\left.\mathrm{X}_{2} \mathrm{X}_{4}, \mathrm{X}_{3} \mathrm{X}_{4}, \mathrm{X}_{4} \mathrm{X}_{4}\right)$, with the $\mathrm{X}_{4}$ being present in all plates examined, males were of two $\mathrm{Y}$ morphotypes $\left(\mathrm{Y}_{1}\right.$ and $\left.\mathrm{Y}_{2}\right)$, with $\mathrm{Y}_{2}$ being less common. Females from CABA were also of all four $\mathrm{X}$ morphotypes in several combinations, whereas males displayed only of the $X_{1}, X_{3}$ and $X_{4}$ (with a predominance of the latter) and a high proportion of the $\mathrm{Y}_{3}$ morphotype, which was only detected at this locality.

\section{DISCUSSION}

This study revealed a surprisingly high chromosome variability in terms of the amount, distribution, and location of the constitutive heterochromatin in the pericentromeric regions of autosome pairs II and III, and in the $\mathrm{X}$ and $\mathrm{Y}$ chromosomes of L. sericata from the three sites sampled in Argentina. There is remarkable conservation of autosomal banding patterns, in contrast to the variety of $\mathrm{X}$ and $\mathrm{Y}$ chromosomes in specimens from all three sites, including four metacentric and three subtelocentric morphologies, with different distributions of pericentromeric heterochromatic blocks. Polymorphisms involving heterochromatin are frequently found in other dipteran insects, mammals, and plants (Baimai, 1998; Rafael \& Tadei, 2000; Rudra \& Bahadur, 2013; Steiner et al., 2014; Siljak-Yakovlev et al., 2017). However, it is not common to find heterochromatic polymorphisms in the same population, as in L. sericata from Argentina. The small number of females used in this study undoubtedly influenced our results and underestimated or skewed the real cytogenetic pattern. Adults arriving together at baits could be related and indicate a higher level of inbreeding than would be expected from a random sample, although for the three Argentinean sites sampled for L. sericata there is no evidence of a geographic barrier to gene flow, isolation by distance or a population genetic structure, as has been detected in the United States and Europe (Picard \& Wells, 2010; Diakova et al., 2018). Therefore, it is difficult to interpret the recorded polymorphism in terms of population genetics (genetic drift, differential selection, migration, etc.).

Cytogenetic studies on L. sericata from several biogeographical regions have revealed intraspecific variability in the morphologies and sizes of $\mathrm{X}$ and $\mathrm{Y}$, in the extent of the $\mathrm{C}$ segments they contain and that the sex chromosomes are more likely to rearrangements by the accumulation of constitutive heterochromatin than the autosomes (Boyes, 1961; El-Bassiony, 2006; Ullerich \& Schöttke, 2006; Acuña-Morera et al., 2011; Chirino et al., 2015; this study). Concerning the content and distribution of heterochromatic blocks on the sex chromosomes, only the Argentinean population is known to have different morphotypes of $\mathrm{X}$ and $\mathrm{Y}$ sex chromosomes. The $\mathrm{X}$ chromosomes of individuals from Argentina, Colombia, and Egypt are

Table 4. Percentage of cytotypes of Lucilia sericata recorded in females and males, for which different numbers of cells were observed, in individuals from CABA, Bernal, and Castelar.

\begin{tabular}{|c|c|c|c|c|c|c|c|c|c|c|}
\hline Locality & Chromosome & Females & & & & Males & & & & \\
\hline Bernal & $\begin{array}{l}\text { Cytotype } \\
\mathrm{N}(\mathrm{n})^{*} \\
\text { Percentage }\end{array}$ & $\begin{array}{l}X_{1} X_{1} \\
7(176) \\
100(100)\end{array}$ & & & & $\begin{array}{l}X_{1} Y_{1} \\
5(38) \\
62.5(63.3)\end{array}$ & $\begin{array}{l}X_{1} Y_{2} \\
3(22) \\
37.5(36.7)\end{array}$ & & & \\
\hline Castelar & $\begin{array}{l}\text { Cytotype } \\
\mathrm{N}(\mathrm{n})^{*} \\
\text { Percentage }\end{array}$ & $\begin{array}{l}X_{1} X_{4} \\
4(22) \\
33.3(25.3)\end{array}$ & $\begin{array}{l}\mathrm{X}_{2} \mathrm{X}_{4} \\
1(15) \\
8.3(17.2)\end{array}$ & $\begin{array}{l}X_{3} X_{4} \\
1(12) \\
8.3(13.8)\end{array}$ & $\begin{array}{l}X_{4} X_{4} \\
6(38) \\
50(43.7)\end{array}$ & $\begin{array}{l}X_{1} Y_{1} \\
4(48) \\
33.3(44.3)\end{array}$ & $\begin{array}{l}X_{2} Y_{1} \\
3(19) \\
25(16.4)\end{array}$ & $\begin{array}{l}X_{3} Y_{1} \\
1(12) \\
8.3(11.5)\end{array}$ & $\begin{array}{l}X_{4} Y_{1} \\
2(20) \\
16.7(19.2)\end{array}$ & $\begin{array}{l}X_{2} Y_{2} \\
2(5) \\
16.7(4.8)\end{array}$ \\
\hline CABA & $\begin{array}{l}\text { Cytotype } \\
\mathrm{N}(\mathrm{n})^{*} \\
\text { Percentage }\end{array}$ & $\begin{array}{l}X_{1} X_{1} \\
2(13) \\
20(17.3)\end{array}$ & $\begin{array}{l}X_{1} X_{2} \\
1(7) \\
10(9.3)\end{array}$ & $\begin{array}{l}X_{3} X_{4} \\
1(4) \\
10(5.3)\end{array}$ & $\begin{array}{l}X_{1} X_{4} \\
6(51) \\
60(68.1)\end{array}$ & $\begin{array}{l}X_{1} Y_{1} \\
2(16) \\
25(14.3)\end{array}$ & $\begin{array}{l}X_{3} Y_{1} \\
2(15) \\
25(13.4)\end{array}$ & $\begin{array}{l}X_{4} Y_{1} \\
1(10) \\
12.5(8.9)\end{array}$ & $\begin{array}{l}X_{4} Y_{3} \\
3(71) \\
37.5(63.4)\end{array}$ & \\
\hline
\end{tabular}

${ }^{*} \mathrm{~N}$ - number of individuals analysed, $\mathrm{n}$ - number of cells examined. 
metacentric, those from Germany are submetacentric and those from Canada and the United Kingdom are telocentric. The comparative analysis of the morphology of the mitotic chromosomes in all these populations of $L$. sericata revealed that the diploid chromosomal complement of the South American populations (Colombia and Argentina) has basic characteristics more similar to each other than to the Old World populations (Germany, England, Egypt) and North America (Canada). The four morphotypes of X described in the Argentinean population are distinguished by the different sizes of their satellites and their content of C-positive constitutive heterochromatin; the X chromosomes of individuals from Colombia are similar to the $\mathrm{X}_{3}$ morphotype from Argentina, but with fully euchromatic satellites (Acuña-Morera et al., 2011). German populations are similar to those in Argentina in that they have the morphotype $\mathrm{X}_{1}$ with a mainly heterochromatic satellite and a C-banded proximal block and a short terminal band on the long arm (Ullerich \& Schöttke, 2006). A similar polymorphism, but with a different geographical distribution, is recorded for Y chromosomes: the Y chromosomes in Argentinean populations are subtelocentric, those in populations in Colombia and Egypt are submetacentric and those in populations in Canada, Germany and United Kingdom are telocentric. The long and short arms of the Y chromosome in Colombian populations are heterochromatic and euchromatic, respectively, whereas those in German populations are heterochromatic, but lack a secondary constriction as in the Argentinean population. Therefore, the chromosomes of $L$. sericata blowflies from different regions differ in their C-banding patterns. The processes of genetic differentiation include chromosomal rearrangements giving rise to diverse chromosome morphologies and variation in intra-specific constitutive heterochromatin, which results in quantitative changes of repetitive DNA sequences that lead to karyotype evolution (Baimai, 1998; Rafael \& Tadei, 2000; He et al., 2003; this study). In $L$. sericata, the sex chromosomes are very variable in the content and distribution of heterochromatic blocks compared with the autosomes. An intra-specific variation in sex chromosomes through the accumulation of constitutive heterochromatin is a common phenomenon in reproductively isolated populations of other widely distributed species of Diptera (Baimai, 1998; Rafael \& Tadei, 2000; He et al., 2003). In addition, chromosome polymorphisms were also detected in the three Argentinean population studied and in one Uruguayan population of Hematobia irritans (Linnaeus, 1758) (Diptera: Muscidae) (Forneris et al., 2015). In this species, there are seven karyotypes with different frequencies in populations, which also differ in chromosome banding, chromosome rearrangements (polymorphisms), and chromosome number. Therefore, qualitative and quantitative variations in heterochromatinization associated with changes in its amount and location both within and between species, appear to be an important step in the morphological differentiation of simple sex chromosome systems.
The karyotype data described herein demonstrate that L. sericata is undergoing chromosomal differentiation and karyotype evolution through the accumulation of heterochromatin in the genome. Genetic differentiation in several populations of a species, such as described here, could lead to evolutionary divergence at the chromosomal level and consequently, to speciation. Cryptic and sibling species, or incipient speciation, are frequently detected first at the cytological level in species of Diptera (Baimai, 1998; He et al., 2003). Future studies using a greater number of females could reveal the evolutionary mechanisms behind the observed cytogenetic differentiation. Karyological studies may also help elucidate the high plasticity of genomes at the chromosomal level, potentially leading to adaptation and speciation.

ACKNOWLEDGEMENTS. This work was supported by the Agencia Nacional de Promoción Científica y Tecnológica (ANPCyT) grants [PICT-2025 and PICT-0604]; Consejo Nacional de Investigaciones Científicas y Técnicas (CONICET) grant [PIP 0281], and Universidad Nacional de Quilmes (UNQ) grant [PUNQ53/1026] from Argentina.

\section{REFERENCES}

Acuña-Morera Y., Cortés-Bernal D., Vargas M., Segura N.A. \& Bello-García F. 2011: Caracterización citogenética de $\mathrm{Lu}$ cilia sericata (Meigen, 1826) (Diptera: Calliphoridae), cepa Bogotá, Colombia. - Rev. Cienc. Salud 9: 111-124.

Agrawal U.R., Bajpai N., Kurahashi H. \& Tewari R.R. 2010: Metaphase karyotypes of four species of Calliphoridae (Diptera). - Chrom. Sci. 3: 49-52.

Ames C. \& Turner B. 2003: Low temperature episodes in development of blowflies: implications for postmortem interval estimation. - Med. Vet. Entomol. 17: 178-186.

BAIMAI V. 1998: Heterochromatin accumulation and karyotypic evolution in some dipteran insects. — Zool. Stud. 37: 75-88.

Boyes J.W. 1961: Somatic chromosomes of higher Diptera: V. Interspecific and intraspecific variation in the Calliphoridae. Can. J. Zool. 39: 549-570.

Boyes J.W. \& Shewell G.E. 1975: Cytotaxonomy of Calliphoridae (Diptera). - Genetica 45: 435-488.

Byrd J.H. \& CASTner J.L. 2001: Forensic Entomology: The Utility of Arthropods in Legal Investigations. CRC Press, Boca Raton, FL, $440 \mathrm{pp}$.

Cáceres C., Segura D.F., Vera M.T., Wornoayporn V., Cladera J.L., Teal P., Sapountzis P., Bourtzis K., Zacharopoulou A. \& Robinson A.S. 2009: Incipient speciation revealed in Anastrepha fraterculus (Diptera; Tephritidae) by studies on mating compatibility, sex pheromones, hybridization, and cytology. Biol. J. Linn. Soc. 97: 152-165.

Centeno N.D., Maldonado M. \& Oliva A. 2002: Seasonal patterns of arthropods occurring on sheltered and unsheltered pig carcasses in Buenos Aires Province (Argentina). - Foren. Sci. Int. 126: 63-70.

Chirino M.G., Folgarait P.J., Gilbert L.E., Lanzavecchia S. \& PAPesChi A.G. 2009: Cytogenetic analysis of three species of Pseudacteon (Diptera, Phoridae) parasitoids of the fire ants using standard and molecular techniques. - Genet. Mol. Biol. 32: 740-747.

Chirino M.G., Rossi L.F., Bressa M.J., Luaces J.P. \& Merani M.S. 2015: Comparative study of mitotic chromosomes in two blowflies, Lucilia sericata and L. cluvia (Diptera, Calliphori- 
dae), by C- and G-like banding patterns and rRNA loci, and implications for karyotype evolution. - Comp. Cytogenet. 9: 103-118.

Diakova A.V., Schepetov D.M., Oyun N.Y., Shatalkin A.I. \& GALINSKAYA T.V. 2018: Assessing genetic and morphological variation in populations of Eastern European Lucilia sericata (Diptera: Calliphoridae). - Eur. J. Entomol. 115: 192-197.

Di Rienzo J.A., Casanoves F., Balzarini M.G., GonzÁlez L., Tablada M. \& Robledo C.W. 2015: Grupo InfoStat. Version 2015. FCA, Universidad Nacional de Córdoba, Argentina. URL: http://www.infostat.com.ar.

EL-Bassiony G.M. 2006: Cytogenetic studies of Calliphora vici$n a$ and Lucilia sericata (Diptera: Calliphoridae) from northwestern Egypt. - J. Egypt. Soc. Parasitol. 36: 23-32.

Forneris N.S., Otero G., Pereyra A., Repetto G., Rabossi A., Quesada-Allué L.A. \& Basso A.L. 2015: High chromosomal variation in wild horn fly Haematobia irritans (Linnaeus) (Diptera, Muscidae) populations. - Comp. Cytogen. 9: 31-50.

GreenBerg B. 1991: Flies as forensic indicators. - J. Med. Entomol. 28: 565-577.

Grewal S.I. \& JIA S. 2007: Heterochromatin revisited. — Nat. Rev. Genet. 8: 35-46.

He L.P., Watabe H.A., Zhang Y.P. \& AotsuKa T. 2003: Karyotype differentiation and reproductive isolation among natural populations of Drosophila lacertosa. - Cell Res. 13: 491-497.

Lockwood A.P.M. 1961: 'Ringer' solutions and some notes on the physiological basis of their ionic composition. - Comp. Biochem. Physiol. 2: 241-289.

Opletalová K., Blaizot X., Mourgeon B., Chêne Y., Creveuil C., Combemale P., Laplaud A.-L., Sohyer-Lebreuilly I. \& DompMartin A. 2012: Maggot therapy for wound debridement: a randomized multicenter trial. - Arch. Dermatol. 148: 433-438.

Picard C.J. \& Wells J.D. 2010: The population genetic structure of North American Lucilia sericata (Diptera: Calliphoridae), and the utility of genetic assignment methods for reconstruction of postmortem corpse relocation. - Foren. Sci. Int. 195: 63-67.

RAfael M.S. \& TADEI W.P. 2000: Heterochromatin variation in chromosomes of Anopheles (Nyssorhynchus) darling Root and A. (N.) nuneztovari Gabaldón (Diptera: Culicidae). - Genet. Mol. Biol. 23: 67-70.
Reeves A. \& Tear J. 2000: MicroMeasure for Windows, v. 3.3. URL: http://www.colostate.edu/Depts/Biology/MicroMeasure.

RUDRA M. \& BAHADUR M. 2013: Heterochromatin variation among the populations of Mus terricolor Blyth, 1851 (Rodentia, Muridae) chromosome type I. - Comp. Cytogenet. 7: 139-151.

Selivon D., Perondini A.L.P. \& Morgante J.S. 2005: A geneticmorphological characterization of two cryptic species of the Anastrepha fraterculus complex (Diptera: Tephritidae). Ann. Entomol. Soc. Am. 98: 367-381.

Siljak-Yakovlev S., Godelle B., Zoldos V., Vallès J., Garnatje T. \& HidALGO O. 2017: Evolutionary implications of heterochromatin and rDNA in chromosome number and genome size changes during dysploidy: A case study in Reichardia genus. - PLoS ONE 12(8): e0182318, 21 pp.

Steiner C.C., Suellen J.C., Marlys L.H. \& Oliver A.R. 2014: Molecular phylogeny and chromosomal evolution of Alcelaphini (Antilopinae). - J. Hered. 105: 324-333.

Stevens J. \& Wall R. 1996: Classification of the genus Lucilia (Diptera: Calliphoridae): a preliminary parsimony analysis. J. Nat. Hist. 30: 1087-1094.

SumNer A.T. 1972: A simple technique for demonstrating centromeric heterochromatin. - Exp. Cell Res. 75: 304-306.

Traut W. 1976: Pachytene mapping in the female silkworm Bombyx mori L. (Lepidoptera). - Chromosoma 58: 275-284.

UlLerich F.H. \& SChÖtTKE M. 2006: Karyotypes, constitutive heterochromatin, and genomic DNA values in the blowfly genera Chrysomya, Lucilia, and Protophormia (Diptera: Calliphoridae). - Genome 49: 584-597.

White M.J.D. 1973: Animal Cytology and Evolution. Cambridge University Press, London, $468 \mathrm{pp}$.

Whitworth T.L. 2010: Keys to the genera and species of blow flies (Diptera: Calliphoridae) of the West Indies and description of a new species of Lucilia Robineau-Desvoidy. - Zootaxa 2663: $1-35$.

Whitworth T.L. 2014: A revision of the Neotropical species of Lucilia Robineau-Desvoidy (Diptera: Calliphoridae). Zootaxa 3810: 1-76.

Received July 7, 2019; revised and accepted June 16, 2020 Published online July 7, 2020 